\title{
SICKNESS PRESENCE, SICK LEAVE AND ADJUSTMENT LATITUDE
}

JOACHIM GERICH

Johannes Kepler University, Linz, Austria

Department of Sociology

\begin{abstract}
Objectives: Previous research on the association between adjustment latitude (defined as the opportunity to adjust work efforts in case of illness) and sickness absence and sickness presence has produced inconsistent results. In particular, low adjustment latitude has been identified as both a risk factor and a deterrent of sick leave. The present study uses an alternative analytical strategy with the aim of joining these results together. Material and Methods: Using a cross-sectional design, a random sample of employees covered by the Upper Austrian Sickness Fund ( $=930)$ was analyzed. Logistic and ordinary least square (OLS) regression models were used to examine the association between adjustment latitude and days of sickness absence, sickness presence, and an estimator for the individual sickness absence and sickness presence propensity. Results: A high level of adjustment latitude was found to be associated with a reduced number of days of sickness absence and sickness presence, but an elevated propensity for sickness absence. Conclusions: Employees with high adjustment latitude experience fewer days of health complaints associated with lower rates of sick leave and sickness presence compared to those with low adjustment latitude. In case of illness, however, high adjustment latitude is associated with a higher probability of taking sick leave rather than sickness presence.
\end{abstract}

Key words:

Sickness absence, Adjustment latitude, Sickness presence, Sick leave, Illness Flexibility Model

\section{INTRODUCTION}

Compared with an extensive history of research on sickness absence, research on sickness presence - attending work despite health complaints that might justify sick leave - has increased during the last decade [1]. At least 2 factors have fuelled interest in this research. Firstly, it has been hypothesized that sickness presence causes more productivity loss and higher organizational costs than sickness absence [2,3]. Secondly, it is believed that sickness presence increases the risk of more serious illness at a later date $[4,5]$. Besides other contextual factors, adjustment latitude has been considered as a possible determinant of the behavior of sickness absence and sickness presence. Adjustment latitude is defined as an employee's opportunity to adjust his or her workload, work time, or work tasks in case of illness [6,7].

Johansson and Lundberg's illness flexibility model [7] stated that adjustment latitude reduces the likelihood of taking sick leave, because the extent to which illness affects workability is attenuated when people are able to adjust their work demands. Conversely, the authors also assumed that an employee with high adjustment latitude has a higher probability of presenteeism. Aronsson and Gustafsson [8] analyzed a concept similar to adjustment latitude, which is how employees control their pace of work with respect to sickness absence and sickness presence. With similar conclusions to Johansson and Lundberg [7], Aronsson and Gustafsson [8]

$\overline{\text { Received: January 8, 2014. Accepted: June 5, }} 2014$.

Corresponding author: J. Gerich, Johannes Kepler University, Department of Sociology, Altenbergerstrasse 69, 4040 Linz, Austria (e-mail: joachim.gerich@jku.at). 
suggested that low control over the pace of work increases the risk of sickness absence at the cost of sickness presence.

The previous research had shown that low adjustment latitude was associated with a higher risk of sick leave, which was consistent with the illness flexibility model. Johansson and Lundberg [7] reported that low adjustment latitude increased the risk of self-reported sickness absence among women. Johansson [6] found that, in contrast to a high level of adjustment latitude, an intermediate level was associated with increased self-reported sickness absence. In a prospective study, Hultin et al. [9] outlined that the lack of baseline adjustment latitude is associated with a higher likelihood of employer-reported sick leave. The effect is the same for men and women, but somewhat higher for men. Similarly, Aronsson and Gustafsson [8] found that the risk of taking sick leave was elevated for employees who cannot determine their pace of work, which is in line with the research following a similar concept incorporated in Karasek's demandcontrol model [10-12].

Contrary to the assumption of the illness flexibility model, Johannson and Lundberg [7] did not confirm a significant relationship between adjustment latitude and presenteeism in a multivariate model adjusted for age, self-rated health, financial situation, and the demands of household tasks. However, a bivariate analysis provided an unexpected significant association between adjustment latitude and presenteeism, showing that low adjustment latitude was connected with higher rates of sickness presence. Similarly, contrary to the illness flexibility model, Aronsson and Gustafsson [8] also found that people with high control of their pace of work had low sickness presence.

Hultin et al. [13] argued that the previous research had viewed adjustment latitude as stable over time, and neglected the individual's dynamics of adjustment latitude, which is expected to vary over time. They used a case-crossover design in which the perceived adjustment latitude at the beginning of an episode of sick leave was compared with the perceived adjustment latitude during a variety of control time periods. Their analysis was restricted to those $35 \%(\mathrm{~N}=432)$ of respondents who reported variations in access to adjustment latitude. Contrary to the results of the previous research, Hultin et al. [13] found that the likelihood of taking sick leave was higher on days with adjustment latitude than it was on days with no adjustment latitude. This effect was not modified by gender, occupational sector, socioeconomic status, length of period of sick leave, baseline adjustment latitude, and attendance requirements. They indicated that their results contradicted those of the previous research, which was attributed to the temporary possibility of adjusting work; therefore, they concluded that further research on the effects of day-to-day variations in adjustment latitude is needed.

As the results of the previous research seem to reflect a considerable amount of inconsistency, the aim of the present study is to suggest an alternative view to integrate the previous findings.

Firstly, the illness flexibility model [7] and Aronsson and Gustafsson's model [8] are based on a restricted decision procedure in which employees who are faced with health complaints must decide between taking sick leave or attending work, despite illness. In the case of health complaints, access to adjustment latitude or control of the pace of work is expected to affect the decision-making process, in that the individual is more likely to opt for sickness presence than for sickness absence.

However, most of the existing research has not analyzed the decision-making process, but has instead examined the relationship between adjustment latitude and the number of days or episodes of sickness absence and sickness presence within a given time period. To analyze a possible effect that adjustment latitude may have on an individual's decision-making processes, it would be 
necessary to examine the relationship using a propensity measure rather than a frequency measure (i.e., days or episodes) of sickness absence or sickness presence. A propensity measure reflects the relative probabilities that an individual will opt for sickness absence or sickness presence in case of illness.

Secondly, the research of Hultin et al. [13] differs from the other designs in 2 respects. The 1st difference is that they assumed temporal variation of adjustment latitude. The 2nd difference is that the research of Hultin et al. is the only study that focuses on the decision-making process by employing a case-crossover design. Taking this approach, Hultin et al. [13] found that a decision in favor of the option of taking sick leave in the case of health complaints is more probable when adjustment latitude is high. However, the weakness of Hultin et al.'s approach is that their analysis was restricted to a relatively small number of respondents who reported variations of adjustment latitude over time.

The present study attempts to integrate both approaches by comparing the association between adjustment latitude and days of sickness absence and presence with an estimator of the individual's decision-making propensity. It is expected that the conflicting results of the previous research can be explained by their focusing on different aspects of sickness absence and sickness presence.

\section{MATERIAL AND METHODS}

\section{Sample}

A standardized questionnaire was mailed out to a random sample of 3000 employees covered by the Upper Austrian Sickness Fund, the mandatory health insurance for all private employees and their relatives in the region of Upper Austria, which has a population of approximately 1.5 million. The data were collected in February 2013 and 930 employees responded to the questionnaire. Respondents who declared more than 60 days of sickness absence or sickness presence were eliminated to avoid a possible bias due to outliers. Another factor to consider is that behavior related to long-term sickness may be different from behavior related to shorter sickness episodes. However, exclusion of those cases only marginally changed the presented results. After excluding this group, 899 respondents remained with available information about self-reported days of sick leave and sickness presence.

One hundred and eighteen respondents (13.1\%) reported 0 days of sick leave and 0 days of sickness presence during the previous year. Individuals who had not experienced any health complaints, leading to either sickness presence or sickness absence, would not contribute any relevant information on their propensity to presenteeism or absenteeism [7,14]. Therefore, the analysis was restricted to the 781 employees who reported at least 1 day of sick leave or 1 day of sickness presence during the previous year.

\section{Measures}

Regarding the days of sick leave, respondents were asked the question: "Approximately how many days were you on sick leave during the last year?" This was followed by an open response field for the number of days.

Regarding the days of sickness presence, respondents were asked the question: "Approximately how many days did you attend work during the past year although your state of health would have justified taking sick leave?" This was followed by an open response field for the number of days. A health event on any one working day is defined to be a health complaint that may lead to a day of sick leave or a day of sickness presence.

The presenteeism-propensity of an individual is defined as the personal propensity to opt to attend work despite illness in case of a health event. The number of health events is estimated by the sum of the reported days of sick leave and sickness presence. Hence, an individual's presenteeism-propensity is estimated by: 
Presenteeism-propensity $=$

Days of sickness presence / Health events $\approx$

Days of sickness presence / (Days of sickness presence + Days of sick leave)

Consequently, an individual's sick leave propensity would be calculated by subtracting his presenteeism-propensity from 1.

Adjustment latitude was measured by the mean responses of 2 items. The items read: "When you feel uncomfortable or out of sorts, do you have the opportunity to adjust your workload to fit your capacity?" and "When you feel ill, do you have the opportunity to postpone some work?" The response categories were: 1 - never, 2 - seldom, 3 - sometimes, and 4 - often.

Potential confounding variables were chosen in order to achieve comparability with the previous research on adjustment latitude and sickness presence or sickness absence $[7,8,13]$.

Information on demography covers age, sex, and occupational status, categorized as: unskilled manual, skilled manual, middle non-manual and higher non-manual.
Factors to consider in the private domain include caregiving duties, covered by the question: "Do you have caregiving duties for others, such as children or the elderly?," and satisfaction with one's financial situation, which was measured on a 4-point rating scale ranging from 1 ("very dissatisfied") to 4 ("very satisfied").

The work domain, regarding attendance requirements (substitutability) was measured by the mean response to 4 statements, each with a 4-point rating which ranged from 1 ("Fully applies") to 4 ("Does not apply at all"). The statements were: "Only a few of my colleagues could take over my work tasks," "Only a few of my colleagues know how to do my work," "I am hard to replace when important decisions have to be made," and "When I am absent for a few days, I have to make up work at a later time."

Actual self-rated health was obtained by using a single-item question [15], with answer categories ranging from 0 (worst imaginable health) to 10 (best imaginable health). Descriptive information about the distribution of all included variables is given in Table 1.

Table 1. Characteristics of the study group

\begin{tabular}{|c|c|c|c|}
\hline \multirow{2}{*}{ Variable } & \multirow{2}{*}{$\mathrm{M} \pm \mathrm{SD}$} & \multicolumn{2}{|c|}{$\begin{array}{c}\text { Employees } \\
(\mathrm{N}=781)\end{array}$} \\
\hline & & $\%$ & $\mathrm{n}$ \\
\hline Age (year) & $43.08 \pm 10.37$ & & \\
\hline$\leq 34$ & & 21.8 & 169 \\
\hline $35-54$ & & 65.5 & 509 \\
\hline$\geq 55$ & & 12.7 & 99 \\
\hline Financial satisfaction & $2.15 \pm 0.66$ & & \\
\hline 1 (very dissatisfied) & & 2.6 & 20 \\
\hline 2 & & 22.4 & 173 \\
\hline 3 & & 62.5 & 483 \\
\hline 4 (very satisfied) & & 12.5 & 97 \\
\hline Self-rated health & $7.09 \pm 1.85$ & & \\
\hline $0-4$ (poor) & & 9.5 & 74 \\
\hline 5-7 (fair) & & 41.5 & 322 \\
\hline 8-10 (good) & & 49.0 & 380 \\
\hline
\end{tabular}


Table 1. Characteristics of the study group - cont.

\begin{tabular}{|c|c|c|c|}
\hline \multirow[t]{2}{*}{ Variable } & \multirow[t]{2}{*}{$\mathrm{M} \pm \mathrm{SD}$} & \multicolumn{2}{|c|}{$\begin{array}{c}\text { Employees } \\
(\mathrm{N}=781)\end{array}$} \\
\hline & & $\%$ & $\mathrm{n}$ \\
\hline Substitutability & $2.56 \pm 0.84$ & & \\
\hline 1 (not at all) & & 8.0 & 61 \\
\hline 2 & & 36.5 & 278 \\
\hline 3 & & 35.8 & 273 \\
\hline 4 (full substitutability) & & 19.7 & 150 \\
\hline Adjustment latitude & $2.34 \pm 0.85$ & & \\
\hline 1 (low) & & 28.2 & 219 \\
\hline 2 & & 30.8 & 239 \\
\hline 3 & & 36.6 & 284 \\
\hline 4 (high) & & 4.5 & 35 \\
\hline Sickness absence (frequency) & $7.06 \pm 9.89$ & & \\
\hline 0 & & 25.2 & 197 \\
\hline $1-5$ & & 39.4 & 308 \\
\hline $6-10$ & & 17.0 & 133 \\
\hline$>10$ & & 18.3 & 143 \\
\hline Presenteeism (frequency) & $8.45 \pm 8.32$ & & \\
\hline 0 & & 12.9 & 101 \\
\hline $1-5$ & & 38.8 & 303 \\
\hline $6-10$ & & 25.6 & 200 \\
\hline$>10$ & & 22.7 & 177 \\
\hline Health events & $15.52 \pm 13.91$ & & \\
\hline $1-10$ & & 48.3 & 377 \\
\hline $11-20$ & & 28.6 & 223 \\
\hline$\geq 21$ & & 23.2 & 181 \\
\hline Presenteeism-propensity & $0.59 \pm 0.34$ & & \\
\hline $0-0.33$ & & 27.5 & 215 \\
\hline $0.34-0.66$ & & 30.3 & 237 \\
\hline$\geq 0.67$ & & 42.1 & 329 \\
\hline \multicolumn{4}{|l|}{ Sex } \\
\hline female & & 50.6 & 394 \\
\hline male & & 49.4 & 384 \\
\hline \multicolumn{4}{|l|}{ Caregiving duties } \\
\hline no & & 56.4 & 435 \\
\hline yes & & 43.6 & 336 \\
\hline
\end{tabular}


Table 1. Characteristics of the study group - cont.

\begin{tabular}{|c|c|c|c|}
\hline \multirow[t]{2}{*}{ Variable } & \multirow[t]{2}{*}{$\mathrm{M} \pm \mathrm{SD}$} & \multicolumn{2}{|c|}{$\begin{array}{c}\text { Employees } \\
(\mathrm{N}=781)\end{array}$} \\
\hline & & $\%$ & $\mathrm{n}$ \\
\hline \multicolumn{4}{|l|}{ Occupational status } \\
\hline unskilled manual & & 13.0 & 94 \\
\hline skilled manual & & 20.4 & 147 \\
\hline middle non-manual & & 44.6 & 322 \\
\hline higher non-manual & & 22.0 & 159 \\
\hline
\end{tabular}

M - mean; SD - standard deviation.

\section{Statistical analysis}

The association between adjustment latitude and sickness absence, sickness presence, the number of health events and presenteeism-propensity are analyzed by logistic regression analyses. For these analyses, all variables except occupational status were dichotomized according to their median values. This is due to the non-normal nature of their distributions, and is consistent with the methods used in most previous studies. Because dichotomization may often lead to seriously biased estimators [16,17], ordinary least square (OLS) regressions were also performed using the original scaling of the variables to assure robustness of the results. Since the number of days of sickness absence and sickness presence, as well as the number of health events, all represent count data, the results of the OLS regressions were also validated with the help of negative binomial regression models with a log link function and robust standard errors.

The sickness presence propensity is measured as a proportion in the range 0 to 1 . A suitable regression model for a continuous proportional outcome, including the 1 and 0 cases, is given by a generalized linear model with a binomial probability distribution and a logit link function [18]. As a check on the robustness of the estimations, this method was applied to the regression model with sickness presence propensity as the outcome. The signs and the structure of significance of the resulting regression coefficients using logit, OLS and the generalized models proved to be the same. Thus, due to the ease of interpretation, only the results of the logit regression are shown.

Zero-order estimates are reported as Pearson's correlation and unadjusted OR. Estimates adjusted for confounders are reported as OR.

\section{RESULTS}

Tables 2 and 3 show the results of the bivariate and multivariate analyses for associations between adjustment latitude and the days of sickness absence, associations between adjustment latitude and the days of sickness presence, the numbers of health events, and the estimated presenteeism-propensity. Bivariate analyses (Table 2 and models 1 in Table 3) show a significant association between adjustment latitude and all dependent variables in the same direction. Compared with employees with low adjustment latitude, those with high adjustment latitude report fewer days of sickness absence $(\mathrm{OR}=0.66)$, fewer days of sickness presence $(\mathrm{OR}=0.33)$, fewer numbers of health events $(\mathrm{OR}=0.39)$, and a lower presenteeismpropensity in case of sickness $(\mathrm{OR}=0.73)$. As shown in Table 1, the mean calculated presenteeism-propensity for the entire sample was 0.59 , which reflects a higher probability of sickness presence compared with that of 
sickness absence; this finding agrees with those of most other studies [2,6-8].

For individuals with reported adjustment latitude below the median, the estimated probability that a day with a health event led to sickness presence is 0.62 ; whereas, for individuals with reported adjustment latitude above the median, the same probability is estimated as 0.55 . Employees with high adjustment latitude reported on average 5.7 days of sickness absence (compared to 8.6 days reported by employees with low adjustment latitude), 6.8 days of sickness presence (compared to 10.4 days reported by employees with low adjustment latitude), and 12.6 days with health events (compared to 19 days reported by employees with low adjustment latitude).

With respect to the bivariate analyses, it has to be considered that high adjustment latitude is related to a higher occupational status, higher financial satisfaction, less substitutability, better health state, and male gender. Within the multivariate models adjusted for the considered confounders, the size of the effect of adjustment latitude on the number of sickness absence days is reduced, and is no longer significant. The odds ratios of adjustment latitude for the other dependent variables remain significant in the same direction.

As one might expect, the strongest predictor for the number of days of sickness absence, the number of days of sickness presence and the number of health events, is self-rated health. However, the presenteeism-propensity is only weakly associated with self-rated health (not significant in multivariate models), which means that the probability of deciding between sickness presence and sickness absence seems not to be affected by the general state of health of the employee.

Table 2. Zero-order correlations

\begin{tabular}{lccccc}
\hline \multirow{2}{*}{ Variable } & \multicolumn{5}{c}{$\begin{array}{c}\text { Pearson's correlation } \\
(\mathrm{N}=722-778)\end{array}$} \\
\cline { 2 - 6 } & $\begin{array}{c}\text { sickness absence } \\
\text { (frequency) }\end{array}$ & $\begin{array}{c}\text { presenteeism } \\
\text { (frequency) }\end{array}$ & health events & $\begin{array}{c}\text { presenteeism- } \\
\text { propensity }\end{array}$ & adjustment latitude \\
\hline Adjustment latitude & $-0.12^{* *}$ & $-0.27^{* *}$ & $-0.25^{* *}$ & $-0.14^{* *}$ & - \\
Sex (women) & $-0.07^{*}$ & $0.07^{*}$ & -0.01 & $0.10^{* *}$ & $-0.12^{* *}$ \\
Age & $0.08^{*}$ & 0.04 & $0.08^{*}$ & 0.02 & 0.01 \\
Occupational status & & & & \\
unskilled manual & $0.11^{* *}$ & $0.09^{*}$ & $0.13^{* *}$ & -0.06 & $-0.17^{* *}$ \\
skilled manual & $0.11^{* *}$ & $0.10^{* *}$ & $0.14^{* *}$ & 0.01 & $-0.11^{* *}$ \\
middle non-manual & $-0.07^{*}$ & -0.07 & $-0.09^{*}$ & 0.04 & 0.04 \\
higher non-manual & $-0.11^{* *}$ & $-0.09^{*}$ & $-0.13^{* *}$ & -0.01 & $0.20^{* *}$ \\
Financial satisfaction & $-0.08^{*}$ & $-0.24^{* *}$ & $-0.20^{* *}$ & $-0.08^{*}$ & $0.20^{* *}$ \\
Caregiving duties & -0.07 & 0.02 & -0.04 & $0.11^{* *}$ & -0.05 \\
Self-rated health & $-0.25^{* *}$ & $-0.41^{* *}$ & $-0.42^{* *}$ & $-0.07^{*}$ & $0.21^{* *}$ \\
Substitutability & $0.18^{* *}$ & $0.10^{* *}$ & $0.19^{* *}$ & $-0.10^{* *}$ & $-0.35^{* *}$ \\
\hline
\end{tabular}

Pearson's correlation (point-biserial correlation for binary variables).

$* \mathrm{p}<0.05 ;{ }^{* *} \mathrm{p}<0.01$. 
Table 3. Odds ratios of adjustment latitude for sickness absence, sickness presence, health events and the propensity of presenteeism (binary logistic regression)

\begin{tabular}{|c|c|c|c|c|c|c|c|c|}
\hline \multirow{3}{*}{ Predictor } & \multicolumn{8}{|c|}{$\begin{array}{c}\text { Employees } \\
(\mathrm{N}=686) \\
(\mathrm{OR}(95 \% \mathrm{CI}))\end{array}$} \\
\hline & \multicolumn{2}{|c|}{$\begin{array}{l}\text { sickness absence } \\
\text { (frequency) }\end{array}$} & \multicolumn{2}{|c|}{$\begin{array}{l}\text { presenteism } \\
\text { (frequency) }\end{array}$} & \multicolumn{2}{|c|}{ health events } & \multicolumn{2}{|c|}{ presenteeism-propensity } \\
\hline & $\operatorname{model} 1^{\mathrm{a}}$ & $\operatorname{model} 2^{\mathrm{b}}$ & model 1 & model 2 & model 1 & model 2 & model 1 & model 2 \\
\hline $\begin{array}{l}\text { Adjustment } \\
\text { latitude }\end{array}$ & $\begin{array}{c}0.66^{*} \\
(0.49-0.89)\end{array}$ & $\begin{array}{c}0.85 \\
(0.61-1.18)\end{array}$ & $\begin{array}{c}0.33^{*} \\
(0.24-0.45)\end{array}$ & $\begin{array}{c}0.42 * \\
(0.30-0.60)\end{array}$ & $\begin{array}{c}0.39^{*} \\
(0.28-0.53)\end{array}$ & $\begin{array}{c}0.53^{*} \\
(0.38-0.76)\end{array}$ & $\begin{array}{c}0.73^{*} \\
(0.54-0.99)\end{array}$ & $\begin{array}{c}0.72^{*} \\
(0.52-0.99)\end{array}$ \\
\hline $\mathrm{R}^{2}$ (Nagelkerke) & 0.01 & 0.10 & 0.08 & 0.24 & 0.07 & 0.24 & 0.01 & 0.06 \\
\hline
\end{tabular}

\section{DISCUSSION}

Based on crude estimates, individuals with higher access to adjustment latitude report fewer days of sickness absence and fewer days of sickness presence, which is in accordance with the result that they experienced fewer days of health complaints.

Focusing on the decision-making process, by examining an employee's propensity to opt for sickness presence or sickness absence in situations where there are health complaints, shows a slightly reduced probability for sickness presence and an elevated probability that those individuals with high adjustment latitude will take sick leave. The association between adjustment latitude and the number of sickness absence days is not significant when adjusted for confounders. However, the introduction of confounders only moderately changed its association with the other dependent variables under study. The present study found that employees with low adjustment latitude have a lower occupational status, report less financial satisfaction, are more easily replaced, and have a worse subjective health status, which fully accounts for the association between adjustment latitude and the number of sickness absence days. In particular, a bad state of health and substitutability are relevant predictors of sickness absence.

One possible explanation for these results is that individuals with high adjustment latitude experience better general working conditions and autonomy, which leads to better health conditions and fewer health complaints $[10,19]$. On the other hand, this autonomy may afford these individuals an adequate response to illness without a special need to justify their behavior. Further analyses, not shown in detail, indicate that individuals with high adjustment latitude more frequently denied that taking sick leave gives a bad impression to others $(r=-0.20, p<0.05)$, that sick leave causes inconvenience to others $(r=-0.22, p<0.05)$, that sick leave is only a measure of last resort $(r=-0.12$, $\mathrm{p}<0.05$ ), or that they have to justify sick leave by providing a medical certificate effective from their 1st day of absence $(r=-0.23, p<0.05)$.

With the exception of the non-significant effect of adjustment latitude on days of sickness absence in the multivariate analysis, the other presented results are in accordance with those of earlier studies. The previous research also found that low adjustment latitude is associated with increased numbers of days of sickness absence and sickness presence [6-9]. Hultin et al.'s [13] case-crossover study 
found a higher probability of sickness absence in times of high adjustment latitude. This finding is also in accordance with the results of the present study, in which the propensity for presenteeism - calculated as the proportion of days with sickness presence to the sum of the days of sickness presence and sickness absence - was found to be lower for employees with high adjustment latitude.

Taking these results together, it can be concluded that individuals with high adjustment latitude have fewer days with health complaints, and therefore fewer days of sickness absence and sickness presence, than those with low adjustment latitude. However, the probability that individuals with high adjustment latitude decide to take sick leave in case of a health complaint instead of attending work despite illness is higher than it is for individuals with low adjustment latitude.

As several studies have shown, the frequencies of sickness absence and sickness presence (measured in days or episodes) are positively correlated [4,8,20-23]. Also, taking a number of other variables into account, research has shown correlations with sickness presence that move in the same direction as the correlation between these variables and sickness absence [20,24,25]. This is because most of the variance shown by both measures is shared by the number of health complaints the individual faces within a given time period. Hence, there is no contradiction in the results that low adjustment latitude is associated with both higher frequencies of sickness absence and sickness presence. This may only indicate that individuals with high adjustment latitude have a better constitution, which is associated with fewer days of experiencing health problems. Whereas most previous research interpreted low adjustment latitude as a risk factor for sickness absence, Hultin et al. [13] found a higher probability for sickness absence in times of high adjustment latitude. Contrary to the other research that focused on prevalence measures (that is, number of days or episodes), Hultin et al. [13] concentrated on the decision-making process, which probably explains their different conclusions. Although Hultin et al. assumed that their different results can be explained by the temporal variation of adjustment latitude, their actual findings show that their focus on the decision-making process may also account for that difference.

Furthermore, the previous results - as well as those of the present study - do not support the illness flexibility model with respect to adjustment latitude, which would suggest that high adjustment latitude is associated with less sickness absence at the cost of elevated sickness presence [7]. Studies that support the hypothesis of an association between adjustment latitude and sickness presence found a reduced, rather than an enhanced, tendency for sickness presence when adjustment latitude is high.

Contrary to other studies, the association between adjustment latitude and days of sickness absence was not significant in the multivariate model. It is difficult to identify the reason for this variation; it may be due to differences in measurement, different cultural backgrounds in Scandinavian regions compared with Austria, or the relatively small sample size of the present study.

Several limitations of the actual results should be taken into account.

Firstly, the measures of sickness absence and sickness presence are based on self-reports, which may be biased due to recall problems or social desirability. Self-reports are the only way to gather data on presenteeism. On the other hand, for sick leave, the results of the previous research suggest that company records or register data are preferable to self-reports [26]. However, due to privacy reasons, personal register data on sick leave are not available in Austria; but fairly close agreement between self-reported data of annual sick-leave and registered data, with equivalent associations on several measures of health was found in previous research [27]. Furthermore, the differences between self-reported and registered sickness absence may also vary due to different organizational standards in reporting sickness absence [27]. Consequently, there may 
be advantages in also using self-reports for sickness absence, especially when making a comparison with sickness presence, for which only self-reports are available.

Secondly, results are based on a cross-sectional design, which clearly limits conclusions about causality and the prospective association between adjustment latitude and the decision-making process. Also, making generalizations about the actual results is limited due to the relatively low response rate to the mailed questionnaires. Therefore, further research will be needed to address this shortcoming. Furthermore, the propensity for presenteeism can only serve as a rough estimator when it is calculated on the basis of the number of days of sickness absence and sickness presence because this calculation does not take into account the episodic character of sickness. It is likely that the number of days of sickness absence or presence that are induced by a certain health complaint are in fact the result of a single decision process made, for example, at the beginning of a sickness episode rather than a repeated process of decisions for each day of the sickness episode. Hence, a validation of the results with a measure that is based on the number of episodes of sickness absence and sickness presence is required.

The findings that adjustment latitude is associated with a lower rate of sickness absence and fewer health problems, and studies that strengthen the suggestion that presenteeism is a risk factor for later health problems [7,22], support the argument that adjustment latitude results in benefits for both employees and employers.

\section{REFERENCES}

1. Johns G. Presenteeism in the workplace. A review and research agenda. J Organ Behav. 2010;31:519-42, http://dx.doi. org/10.1002/job.630.

2. Cooper C, Dewe P. Well-being: Absenteeism, presenteeism, costs and challenges. Occup Med. 2008;58:522-4, http://dx.doi.org/10.1093/occmed/kqn124.
3. Biron C, Saksvik PO. Sickness presenteeism and attendance pressure factors: Implications for practice. In: Quick J, Cooper CL, editors. Handbook of organizational and work psychology. New York: John Wiley; 2010. p. 77-96.

4. Taloyan M, Aronsson G, Leineweber C, Hanson LM, Alexanderson K, Westerlund H. Sickness presenteeism predicts suboptimal self-rated health and sickness absence: A nationally representative study of the Swedish working population. PLos One. 2012;7:1-8, http://dx.doi.org/10. 1371/journal.pone.0044721.

5. Bergström G, Bodin L, Hagberg J, Lindh T, Aronsson G, Josephson M. Does sickness presenteeism have an impact on future general health? Int Arch Occup Environ Health. 2009;82:1179-90, http://dx.doi.org/10.1007/s00420009-0433-6.

6. Johansson G. The illness flexibility model and sickness absence. Thesis. Stockholm: Karolinska Institutet; 2007.

7. Johansson G, Lundberg I. Adjustment latitude and attendance requirements as determinants of sickness absence or attendance. Empirical tests of the illness flexibility model. Soc Sci Med. 2004;58:1857-68, http://dx.doi.org/10.1016/ S0277-9536(03)00407-6.

8. Aronsson G, Gustafsson K. Sickness presenteeism: Prevalence, attendance-pressure factors, and an outline of a model for research. J Occup Environ Med. 2005;47:958-66, http://dx.doi.org/10.1097/01.jom.0000177219.75677.17.

9. Hultin H, Hallqvist J, Alexanderson K, Johansson G, Lindholm C, Lundberg I, et al. Low level of adjustment latitude - A risk factor for sickness absence. Eur J Publ Health. 2010;20:682-8, http://dx.doi.org/10.1093/eurpub/ ckp240.

10. Karasek R, Theorell T. Health work: Stress, productivity and the reconstructions of working life. New York: Basic Books; 1990.

11. Kivimaki M, Vahtera J, Pentti J, Ferrie JE. Factors underlying the effect of organisational downsizing on health of employees: Longitudinal cohort study. BMJ. 2000;320: 971-5, http://dx.doi.org/10.1136/bmj.320.7240.971. 
12. Gimeno D, Benavides FG, Amick BC, Benach J, Martínez JM. Psychosocial factors and work related sickness absence among permanent and non-permanent employees. J Epidemiol Community Health. 2004;58:870-6, http://dx. doi.org/10.1136/jech.2003.016634.

13. Hultin H, Hallqvist J, Alexanderson K, Johansson G, Lindholm C, Lundberg I, et al. Lack of adjustment latitude at work as a trigger of taking sick leave - A Swedish case-crossover study. PLos One. 2013;8:1-8, http://dx.doi.org/10.1371/ journal.pone.0061830.

14. Jourdain G, Vézina M. How psychological stress in the workplace influences presenteeism propensity: A test of the Demand-Control-Support model. Eur J Work Organ Psychol. 2013;23(4):483-96, http://dx.doi.org/10.1080/13594 32X.2012.754573.

15. Nübling M, Stößel U, Hasselhorn HM, Michaelis M, Hofmann F. [Methods for gathering mental stress. Test of an inventory]. Dortmund: Nw-Verlag; 2005. German.

16. Royston P, Altman DG, Sauerbrei W. Dichotomizing continuous predictors in multiple regression: A bad idea. Stat Med. 2006;25:127-41, http://dx.doi.org/10.1002/sim.2331.

17. MacCallum RC, Zhang S, Preacher KJ, Rucker DD. On the practice of dichotomization of quantitative variables. Psychol Methods. 2002;7:19-40, http://dx.doi.org/10.1037/1082989X.7.1.19.

18. Papke L, Wooldridge J. Econometric methods for fractional response variables with an application to 401 (K) plan participation rates. J Appl Econometrics. 1996;11:619-32, http://dx.doi.org/10.1002/(SICI)1099-1255 (199611)11:6\%3C619::AID-JAE418\%3E3.0.CO;2-1.

19. Jones F, Fletcher B. Job control, physical health and psychological well-being. In: Schabracq MJ, Winnubst JAM, Cooper CL, editors. The handbook of work \& health psychology. Chichester: John Wiley; 2003. p. 121-42.

20. Leineweber C, Westerlund H, Hagberg J, Svedberg P, Alexanderson K. Sickness presenteeism is more than an alternative to sickness absence: Results from the population-based SLOSH study. Int Arch Occup Environ Health. 2012;85:905-14, http://dx.doi.org/10.1007/ s00420-012-0735-y.

21. Hansen CD, Andersen JH. Going ill to work - What personal circumstances, attitudes and work-related factors are associated with sickness presenteeism? Soc Sci Med. 2008;67: 956-64, http://dx.doi.org/10.1016/j.socscimed.2008.05.022.

22. Caverley N, Cunningham BJ, MacGregor JN. Sickness presenteeism, sickness absenteeism, and health following restructuring in a public service organization. J Manag Stud. 2007;44:304-19, http://dx.doi.org/10.1111/j.1467-6486. 2007.00690.x.

23. Aronsson G, Gustafsson K, Dallner M. Sick but yet at work. An empirical study of sickness presenteeism. Epidemiol Community Health. 2000;54:502-9, http://dx.doi.org/ 10.1136/jech.54.7.502.

24. Böckerman P, Laukkanen E. Predictors of sickness absence and presenteeism: Does the pattern differ by a respondent's health? J Occup Environ Med. 2010;52:332-5, http:// dx.doi.org/10.1097/JOM.0b013e3181d2422f.

25. Elstad JI, Vabø M. Job stress, sickness absence and sickness presenteeism in Nordic elderly care. Scand J Publ Health. 2008;36:467-74, http://dx.doi.org/10.1177/ 1403494808089557.

26. Poppel MN, de Vet HC, Koes BW, Smid T, Bouter LM. Measuring sick leave: A comparison of self-reported data on sick leave and data from company records. Occup Med. 2002;52:485-90, http://dx.doi.org/10.1093/ occmed/52.8.485.

27. Ferrie JE, Kivimäki M, Head J, Shipley MJ, Vahtera J, Marmot MG. A comparison of self-reported sickness absence with absences recorded in employers' registers: Evidence from the Whitehall II study. Occup Environ Med. 2005;62:74-9, http://dx.doi.org/10.1136/oem. 2004.013896.

This work is available in Open Access model and licensed under a Creative Commons Attribution-NonCommercial 3.0 Poland License - http://creativecommons.org/ licenses/by-nc/3.0/pl/deed.en. 